Original Article

\title{
Comparison of pain, disorder, back performance, and psychological factors in patients with low back pain and radicular pain
}

\author{
Seunghwan Kim, PT, MS'1), Jung Hyun Kim, PT, PhD²), You Lim Kim, PT, PhD ${ }^{1)}$, \\ Suk Min LeE, PT, $\mathrm{PhD}^{1)^{*}}$ \\ 1) Department of Physical Therapy, Sahmyook University: 26-21 Gongneung 2-dong, Nowon-gu, \\ Seoul 139-742, Republic of Korea \\ 2) Department of Physical Therapy, College of Health Welfare, Woosong University, Republic of Korea
}

\begin{abstract}
Purpose] This study investigated the relationship between pain intensity, lumber disability, and psychological factors in patients with low back pain. [Subjects and Methods] A total of 166 outpatients (116 female, 50 male) with chronic low back pain presenting for physical therapy participated in this study. Patients were divided into two groups: those with low back pain alone and those with both low back pain and radicular pain. Pain intensity and lumbar disability were measured using a visual analogue scale and the Roland-Morris Disability Questionnaire. Psychological factors, such as self-efficiency, fear avoidance, and depression were measured using the Chronic Pain Self-efficacy Scale, Fear-Avoidance Beliefs Questionnaire, and Beck Depression Index, respectively. [Results] Patients with low back pain with radicular pain had greater pain and lumber disability and lower psychological factors compared with patients with chronic low back pain alone. [Conclusion] Our findings indicate the presence of low back pain with radicular pain is more related to pain, LBP disability index, Back performance, Self-efficiency (Pain, Function, Symptom), Fear-avoidance (body, work) and depression factors than low back pain. Considering the relationships between in pain, LBP disability index, Back performance, Self-efficiency (Pain, Function, Symptom), Fear-avoidance (body, work) and depression factors in patients with low back pain, therapeutic intervention for not only pain and dysfunction, but also psychological factors is needed.

Key words: Radicular pain, Lumber disability, Psychological factors
\end{abstract}

(This article was submitted Aug. 20, 2017, and was accepted Oct. 24, 2017)

\section{INTRODUCTION}

Low back pain (LBP) is experienced by $50-90 \%$ of the total population at least once in their lifetime ${ }^{1)}$. Chronic LBP during more than 3-6 months causes functional movement limitations and low quality of life (QOL) ${ }^{2,3)}$. Also, the degree of LBP differs depending on a variety of social and psychological factors ${ }^{4}$. Thus, we investigated the relationship between pain intensity, lumber disability, and psychological factors in patients with LBP for the first time.

It is very important to evaluate the trunk exercise ability of patients with chronic pain when considering treatment ${ }^{5)}$. When back pain persists chronically for several months or more, the muscular strength of the lumbar region weakens compared with those who do not have repeated back pain ${ }^{6}$. As a result, the patient experiences reduced physical activity, has problems with activities of daily living, and faces psychological factors such as depression and lethargy ${ }^{7}$. Among psychological factors, depression, anxiety, counterstrategy, and fear-avoidance beliefs are related to continuous disabilities induced by LBP ${ }^{8-10)}$. Caby et al. applied the trunk exercise of spinal function recovery program to patients with chronic LBP and found that the

*Corresponding author. Suk Min Lee (E-mail: leesm@syu.ac.kr)

(C2018 The Society of Physical Therapy Science. Published by IPEC Inc.

This is an open-access article distributed under the terms of the Creative Commons Attribution Non-Commercial No Derivatives (by-nc-nd) License. (CC-BY-NC-ND 4.0: https://creativecommons.org/licenses/by-nc-nd/4.0/) 
Table 1. General characteristics of patients $(\mathrm{N}=166)$

\begin{tabular}{|c|c|c|c|}
\hline & & $\begin{array}{l}\text { Local low back pain group } \\
\qquad(\mathrm{n}=73)\end{array}$ & $\begin{array}{c}\text { Low back pain with related leg } \\
\text { pain group }(n=93)\end{array}$ \\
\hline \multirow[t]{2}{*}{ Gender } & Male & $26^{\mathrm{a}}$ & 24 \\
\hline & Female & 47 & 69 \\
\hline \multirow[t]{5}{*}{ Age (years) } & $20-29$ & 16 & 11 \\
\hline & $30-39$ & 17 & 14 \\
\hline & $40-49$ & 13 & 22 \\
\hline & $50-59$ & 14 & 28 \\
\hline & $60-69$ & 13 & 18 \\
\hline \multirow[t]{5}{*}{ Height $(\mathrm{cm})$} & $140-149$ & 0 & 4 \\
\hline & $150-159$ & 22 & 30 \\
\hline & $160-169$ & 26 & 36 \\
\hline & $170-179$ & 24 & 16 \\
\hline & 180-189 & 1 & 7 \\
\hline \multirow[t]{6}{*}{ Weight (kg) } & $40-49$ & 9 & 6 \\
\hline & $50-59$ & 30 & 33 \\
\hline & $60-69$ & 16 & 36 \\
\hline & $70-79$ & 12 & 11 \\
\hline & $80-89$ & 5 & 4 \\
\hline & $90-99$ & 1 & 3 \\
\hline \multirow[t]{2}{*}{ Duration } & Less than 1 year & 32 & 24 \\
\hline & 1 year or more & 41 & 69 \\
\hline
\end{tabular}

aNumber.

exercise reduced their anxiety and depression ${ }^{11)}$.

The distribution of LBP has two patterns. First, LBP can be caused by the stimulation of dolorific nerves of the spine and its neighboring tissues; the other is the radicular pain caused by the pressurized nerve root ${ }^{12}$. The presence of radicular pain is a significant criterion to diagnose $\mathrm{LBP}^{13}$. . Leg pain related to LBP is a significant risk factor and can result in a poor prognosis ${ }^{14)}$. Namely, patients with low body pain related to LBP have a longer duration of illness and more functional disabilities than patients with only local $\mathrm{LBP}^{15)}$. Also, patients with radicular pain have been found to have larger activity limitations, greater depression, more fear of exercise, and lower health status than patients with only local $\mathrm{LBP}^{16)}$. This indicates that the presence of radicular pain should be taken into account when evaluating the functional limitations induced by LBP ${ }^{17}$. Unfortunately, few previous studies have compared Back performance, pain, and psychological pain depending on pain regions. Moreover, not much research on the correlation between these variables within patients with local LBP and patients with LBP with radicular pain groups has been conducted. Hence, it is necessary to investigate the relationship between these factors in order to develop more effective treatment approaches. We therefore investigated pain, LBP disability index, back performance, and psychological factors in two groups - patients with chronic LBP only (local LBP group) and patients with LBP with radicular pain group — and identified the variables that explain disabilities in each group.

\section{SUBJECTS AND METHODS}

A total of 166 outpatients with LBP who were prescribed physical treatment in two hospitals, participated in this study. All patients met the selection criteria, which were as follows: more than 20 years of age, more than 3 months of LBP, access to medical history, the ability to read and understand the questions and questionnaire items, and the ability to perform the Back performanceal test with no problems. Those who had a damaged central nervous system, exercise deficiency, a tumor on the spine or underwent a surgical operation of the spine, were pregnant, or failed to understand and follow the instructions because of cognitive problems were excluded from the study. The purpose and contents of this study were explained to patients prior to experimentation, and written informed consent was acquired prior to the study. The experiment was approved by the Institutional Research Board of Sahmyook University.

Patients ( $\mathrm{n}=166)$ were divided into a local LBP group $(\mathrm{n}=73$, LBP only) and into LBP with radicular pain group $(\mathrm{n}=93$, LBP and radicular pain in their buttocks and/or legs). Four physical therapists evaluated the patients; all therapists fully understood the contents of the evaluation form and had more than five years clinical experience. General characteristics of the patients are presented in Table 1; these data were collected from a standardized questionnaire that included questions on gender, age, weight, height, a pain region, and duration of illness. Pain, LBP disability index, Back performance, and self-efficacy, fear-avoidance beliefs, and depression were collected from physical therapists' assessment and the self-report questionnaire.

To determine the degree of pain experienced, we used the visual analogue scale (VAS), which is widely used in pain research and has a high reliability, validity, and sensitivity ${ }^{18}$. As a preferred functional disability measurement tool, LBP 
Table 2. Differences in pain, low back pain disability index, trunk function, and psychological factors between the local low back pain group and low back pain with leg pain group

\begin{tabular}{lcc}
\hline \multicolumn{1}{c}{ Variation } & $\begin{array}{c}\text { Local low back pain group } \\
(\mathrm{n}=73)\end{array}$ & $\begin{array}{c}\text { Low back pain with related } \\
\text { leg pain group }(\mathrm{n}=93)\end{array}$ \\
\hline Pain (scores) & $4.14 \pm 1.53^{\mathrm{a}}$ & $5.59 \pm 1.71^{* * *}$ \\
LBP disability index (scores) & $7.12 \pm 3.86$ & $10.49 \pm 4.59^{* * *}$ \\
Back performance (scores) & $3.04 \pm 1.66$ & $4.35 \pm 2.07^{* * *}$ \\
Self-efficacy-pain (scores) & $27.07 \pm 5.59$ & $23.47 \pm 5.65^{* * *}$ \\
Self-efficacy-function (scores) & $55.81 \pm 10.52$ & $50.18 \pm 11.24^{* *}$ \\
Self-efficacy-symptom (scores) & $41.56 \pm 9.39$ & $38.40 \pm 8.83^{*}$ \\
Fear-avoidance-body (scores) & $12.93 \pm 4.11$ & $16.24 \pm 4.34^{* * *}$ \\
Fear-avoidance-work (scores) & $19.25 \pm 7.78$ & $22.52 \pm 8.00^{* *}$ \\
Depression (scores) & $7.60 \pm 4.66$ & $9.39 \pm 5.35^{*}$ \\
\hline
\end{tabular}

${ }^{a}$ Data are expressed as the mean $\pm \mathrm{SD}$ (standard deviation).

$* \mathrm{p}<0.05 ; * * \mathrm{p}<0.01 ; * * * \mathrm{p}<0.001$

disability index (Roland-Morris Disability Questionnaire: RMDQ) was proved to be reliable and valid ${ }^{19,20)}$. The Back Performance Scale (BPS) is used to test five types of physical performance ability for activities of daily living that require trunk mobility. The test-retest reliability of this measurement tool has been reported as good, at $0.996^{5,21)}$. The Chronic Pain Self-efficacy Scale (CPSS) was designed to measure a patient's self-efficacy in responding to chronic pain ${ }^{22}$. The FearAvoidance Beliefs Questionnaire (FABQ) is a self-report questionnaire used to evaluate fear-avoidance beliefs in the physical and occupational activities of patients with LBP. Regarding the internal consistency of the Korean FABQ, Cronbach's $\alpha$ was $0.90(\mathrm{p}<0.01)$, which indicates a high level of internal consistency. According to previous test-retest reliability evaluations, the correlation coefficient was $0.95(95 \% \mathrm{CI}=0.92-0.97)$, which indicates a high reliability, and validity was found to be highly correlated $(\mathrm{p}<0.01)^{23)}$. The Beck Depression Scale (BDS) uses a 3-point Likert type response scale to 21 questions. In the scale, a total of 0-13 points are considered 'normal', 14-25 points to indicate 'depression', and 26-63 points to indicate 'severe depression'. Regarding the reliability of this tool, Cronbach's $\alpha$ has been reported at $0.86^{24)}$.

The data collected in this study were analyzed using SPSS ver. 19.0. To identify the general characteristics of patients, frequency analysis was conducted. To compare pain, LBP disability index, Back performance, self-efficacy, fear-avoidance beliefs, and depression between the two groups depending on pain regions, independent sample t-tests were conducted. To analyze the correlations between pain, LBP disability index, Back performance, self-efficacy, fear-avoidance beliefs, and depression in each group depending on pain regions, Pearson's correlation coefficient was used. The statistical significance level of all data was set to $\mathrm{p}<0.05$.

\section{RESULTS}

Statistically significant differences in pain, LBP disability index, Back performance, Self-efficiency (Pain, Function, Symptom), Fear-avoidance (body, work) and Depression factors were found between the local LBP group and LBP with radicular pain group (all, $\mathrm{p}<0.05$ ) (Table 2).

Within the local LBP group, LBP disability index, Back performance, Self-efficacy-function, Self-efficacy-symptom showed no correlations with fear avoidance-work. However, in the LBP with radicular pain group, pain, LBP disability index, Back performance, depression, and self-efficacy were all correlated with fear avoidance-work (all, p<0.05) (Table 3).

\section{DISCUSSION}

This is the study to have compared pain, LBP disability index, Back performance, and psychological factors according to pain regions. In a previous study with 428 patients with chronic LBP, patients who tested positive in straight leg raising test and had radicular pain in the region below the knees showed a higher level of pain and more functional disabilities than patients with LBP only ${ }^{25)}$. Similarly, the present study revealed that patients with LBP with radicular pain had significantly worse pain, functional disabilities, and Back performance than patients with LBP only. Furthermore, we found that patients with LBP with radicular pain had significantly worse self-efficacy, depression, and fear-avoidance beliefs than patients with LBP only.

Many studies have reported the relationship between the psychological factors related to LBP and functional disabilities. For instance, Arnstein ${ }^{26)}$ reported that chronic pain brought about changes in diverse psychological factors, including individuals' physical functional disabilities, depression, self-efficacy, and lifestyles, resulting from variable and complicated phenomena. According to Boa et al. ${ }^{27}$, the degree of pain in patients with chronic LBP had a significant negative correlation with self-efficacy for pain care and symptom action, whereas no correlation was found between self-efficacy for function and physical performance ability. In this study, pain had significant correlations with Back performance, self-efficacy, fear- 
Table 3. Correlations between pain, disorder index, trunk function, and psychological factors in the local low back pain group and low back pain with related leg pain group

\begin{tabular}{|c|c|c|c|c|c|c|c|c|c|}
\hline Variation & Pain & $\begin{array}{c}\text { LBP } \\
\text { disability } \\
\text { index }\end{array}$ & $\begin{array}{c}\text { Back } \\
\text { performance }\end{array}$ & $\begin{array}{c}\text { Self- } \\
\text { efficacy- } \\
\text { pain }\end{array}$ & $\begin{array}{c}\text { Self- } \\
\text { efficacy- } \\
\text { function }\end{array}$ & $\begin{array}{c}\text { Self- } \\
\text { efficacy- } \\
\text { symptom }\end{array}$ & $\begin{array}{l}\text { Fear-avoid- } \\
\text { ance-body }\end{array}$ & $\begin{array}{l}\text { Fear-avoid- } \\
\text { ance -work }\end{array}$ & Depression \\
\hline & & \multicolumn{8}{|c|}{ Low back pain with related leg pain group } \\
\hline Pain & - & $0.623^{*}$ & $0.563^{*}$ & $-0.405^{*}$ & $-0.367^{*}$ & -0.186 & $0.404^{*}$ & $0.469^{*}$ & $0.239^{*}$ \\
\hline Disorder index & $0.655^{*}$ & - & $0.736^{*}$ & $-0.444^{*}$ & $-0.496^{*}$ & $-0.239^{*}$ & $0.367^{*}$ & $0.400^{*}$ & $0.497^{*}$ \\
\hline Back performance & $0.511^{*}$ & $0.828^{*}$ & - & $-0.393^{*}$ & $-0.550^{*}$ & $-0.276^{*}$ & $0.286^{*}$ & $0.285^{*}$ & $0.414^{*}$ \\
\hline Self-efficacy-pain & $-0.541^{*}$ & $-0.407^{*}$ & $-0.431^{*}$ & - & $0.508^{*}$ & $0.513^{*}$ & $-0.281^{*}$ & $-0.369^{*}$ & $-0.426^{*}$ \\
\hline Self-efficacy-function & $-0.486^{*}$ & $-0.512^{*}$ & $-0.568^{*}$ & $0.688^{*}$ & - & $0.632^{*}$ & $-0.363^{*}$ & $-0.411^{*}$ & $-0.372^{*}$ \\
\hline Self-efficacy-symptom & $-0.587^{*}$ & $-0.361^{*}$ & $-0.289^{*}$ & $0.497^{*}$ & $0.526^{*}$ & - & $-0.341^{*}$ & $-0.377^{*}$ & $-0.244^{*}$ \\
\hline Fear-avoidance-body & $0.293^{*}$ & $0.287^{*}$ & 0.193 & -0.221 & $-0.281^{*}$ & -0.146 & - & $0.510^{*}$ & 0.184 \\
\hline Fear-avoidance-work & 0.146 & 0.193 & 0.189 & $-0.248^{*}$ & -0.094 & -0.169 & $0.465^{*}$ & - & $0.229^{*}$ \\
\hline \multirow[t]{2}{*}{ Depression } & $0.378^{*}$ & $0.401^{*}$ & $0.479^{*}$ & $-0.396^{*}$ & $-0.475^{*}$ & $-0.361^{*}$ & 0.189 & 0.188 & \multirow[t]{2}{*}{-} \\
\hline & & & & cal lo & $1 \mathrm{~g}$ & & & & \\
\hline
\end{tabular}

$* \mathrm{p}<0.05$.

avoidance beliefs, and depression, in both groups.

In the LBP with radicular pain group, Back performance had correlation with fear-avoidance beliefs; no such correlation was found in the local LBP group. These results may suggest that the local LBP group experienced less pain than the LBP with radicular pain group, because lower levels of pain may influence Back performance and self-efficacy but fail to influence fear-avoidance beliefs. A score of more than 14-15 points of fear-avoidance indicates fear-avoidance beliefs ${ }^{28}$, which was found in the LBP with radicular pain group. According to the research of $\mathrm{Kim}^{29}$ ) on shipyard workers with LBP, the sub-group of workers with radicular pain held stronger fear-avoidance beliefs than the group of workers without radicular pain. Our own findings thus support this finding.

In this study, within the local LBP group, pain and LBP disability had significant correlations with Back performance, self-efficacy, and depression, but no significant correlation with fear avoidance-work. But, in the LBP with radicular pain group, we also identified correlations between pain and LBP disability with back performance, self-efficacy, fear-avoidance beliefs, and depression. This was the same result as the study that the LBP with radicular pain group felt more fear-avoidance response ${ }^{29)}$. In the study of fear-avoidance reaction for patients with low back pain, FABQ-PA was related to physical activity, FABQ-W was related to work. FABQ-W is related to activity limitation and loss of work rather than FABQ-PA ${ }^{30,31)}$. Therefore, FABQ-W has a higher fear-avoidance response in relation to work than FABQ-PA.

Future studies should investigate whether the cause of the lower body pain in patients with both lower body pain and LBP is caused by nerve root pressure, or the tension of waist muscles, ligaments, or gluteal muscles. Future work could also divide the regions of radicular pain into the region over the knees, and into the region below the knees to compare pain, waist disabilities, Back performance, and psychological factors before and after LBP treatment. Such studies would allow us to identify variables that react with a patient's treatment.

These results may help determine criteria for whether a patient with LBP has lower body pain. Furthermore, these findings not only highlight the importance of treatment of pain and the evaluation of functional status, but also therapeutic interventions that target psychological factors.

\section{Funding}

This paper was supported by the Academic Research Fund of Dr. Myung Ki (MIKE) Hong.

\section{REFERENCES}

1) Christie HJ, Kumar S, Warren SA: Postural aberrations in low back pain. Arch Phys Med Rehabil, 1995, 76: 218-224. [Medline] [CrossRef]

2) Waddell G: Biopsychosocial analysis of low back pain. Baillieres Clin Rheumatol, 1992, 6: 523-557. [Medline] [CrossRef]

3) Uluğ N, Yakut Y, Alemdaroğlu İ, et al.: Comparison of pain, kinesiophobia and quality of life in patients with low back and neck pain. J Phys Ther Sci, 2016, 28: 665-670. [Medline] [CrossRef]

4) Frymoyer JW: Back pain and sciatica. N Engl J Med, 1988, 318: 291-300. [Medline] [CrossRef]

5) Magnussen L, Strand LI, Lygren H: Reliability and validity of the back performance scale: observing activity limitation in patients with back pain. Spine, 2004, 29: 903-907. [Medline] [CrossRef]

6) Nicolaisen T, Jørgensen K: Trunk strength, back muscle endurance and low-back trouble. Scand J Rehabil Med, 1985, 17: 121-127. [Medline]

7) Heaton RK, Getto CJ, Lehman RA, et al.: A standardized evaluation of psychosocial factors in chronic pain. Pain, 1982, 12: 165-174. [Medline] [CrossRef]

8) Burton AK, Tillotson KM, Main CJ, et al.: Psychosocial predictors of outcome in acute and subchronic low back trouble. Spine, 1995, 20: 722-728. [Medline] [CrossRef] 
9) Gatchel RJ, Polatin PB, Mayer TG: The dominant role of psychosocial risk factors in the development of chronic low back pain disability. Spine, 1995, 20: 2702-2709. [Medline] [CrossRef]

10) Lacroix JM, Powell J, Lloyd GJ, et al.: Low-back pain. Factors of value in predicting outcome. Spine, 1990, 15: 495-499. [Medline] [CrossRef]

11) Caby I, Vanvelcenaher J, Letombe A, et al.: Effects of a five-week intensive and multidisciplinary spine-specific functional restoration program in chronic low back pain patients with or without surgery. Ann Phys Rehabil Med, 2010, 53: 621-631. [Medline] [CrossRef]

12) Last AR, Hulbert K: Chronic low back pain: evaluation and management. Am Fam Physician, 2009, 79: 1067-1074. [Medline]

13) Wipf JE, Deyo RA: Low back pain. Med Clin North Am, 1995, 79: 231-246. [Medline] [CrossRef]

14) Hill JC, Dunn KM, Lewis M, et al.: A primary care back pain screening tool: identifying patient subgroups for initial treatment. Arthritis Rheum, 2008, 59: 632-641. [Medline] [CrossRef]

15) Andersson GB, Svensson HO, Odén A: The intensity of work recovery in low back pain. Spine, 1983, 8: 880-884. [Medline] [CrossRef]

16) Meir L, Strand LI, Alice K: A model for pain behavior in individuals with intellectual and developmental disabilities. Res Dev Disabil, 2012, 33: 1984-1989. [Medline] [CrossRef]

17) Ren XS, Selim AJ, Fincke G, et al.: Assessment of functional status, low back disability, and use of diagnostic imaging in patients with low back pain and radiating leg pain. J Clin Epidemiol, 1999, 52: 1063-1071. [Medline] [CrossRef]

18) Jensen MP, Karoly P, Braver S: The measurement of clinical pain intensity: a comparison of six methods. Pain, 1986, 27: 117-126. [Medline] [CrossRef]

19) Deyo RA, Battie M, Beurskens AJ, et al.: Outcome measures for low back pain research. A proposal for standardized use. Spine, 1998, 23: 2003-2013. [Medline] [CrossRef]

20) Boonstra AM, Schiphorst Preuper HR, Reneman MF, et al.: Reliability and validity of the visual analogue scale for disability in patients with chronic musculoskeletal pain. Int J Rehabil Res, 2008, 31: 165-169. [Medline] [CrossRef]

21) Strand LI, Moe-Nilssen R, Ljunggren AE: Back Performance Scale for the assessment of mobility-related activities in people with back pain. Phys Ther, 2002, 82: 1213-1223. [Medline]

22) Anderson KO, Dowds BN, Pelletz RE, et al.: Development and initial validation of a scale to measure self-efficacy beliefs in patients with chronic pain. Pain, 1995, 63: 77-84. [Medline] [CrossRef]

23) Joo MK, Kim TY, Kim JT, et al.: Reliability and validity of the Korean version of the fear-avoidance beliefs questionnaire. 2008, 16: 24-30.

24) Nielsen AC 3rd, Williams TA: Prevalence by Self-report questionnaire and recognition by nonpsychiatric physicians. Arch Gen Psychiatry, 1980, 37: 9991004. [Medline] [CrossRef]

25) Selim AJ, Ren XS, Fincke G, et al.: The importance of radiating leg pain in assessing health outcomes among patients with low back pain. Results from the Veterans Health Study. Spine, 1998, 23: 470-474. [Medline] [CrossRef]

26) Arnstein P: Chronic neuropathic pain: issues in patient education. Pain Manag Nurs, 2004, 5: 34-41. [Medline] [CrossRef]

27) Boa A, Ao E: Pain intensity, self-efficacy and physical p6rformance in patients with chronic low back pain. Int J Ther Rehabil, $2010,17: 10$.

28) Crombez G, Vlaeyen JW, Heuts PH, et al.: Pain-related fear is more disabling than pain itself: evidence on the role of pain-related fear in chronic back pain disability. Pain, 1999, 80: 329-339. [Medline] [CrossRef]

29) Kim RJ: The analysis of effect factors on fear-avoidance beliefs related low back pain in the shipyard workers. Silla University, master degree, Pusan.

30) Fritz JM, George SZ: Identifying psychosocial variables in patients with acute work-related low back pain: the importance of fear-avoidance beliefs. Phys Ther, 2002, 82: 973-983. [Medline]

31) Grotle M, Vøllestad NK, Veierød MB, et al.: Fear-avoidance beliefs and distress in relation to disability in acute and chronic low back pain. Pain, 2004, 112: 343-352. [Medline] [CrossRef] 